\title{
Oral and Intravenous Itraconazole for Systemic Fungal Infections in Neutropenic Haematological Patients: Meeting Report
}

\author{
H.G. Prenticea ${ }^{\text {a }}$ D. Caillot ${ }^{b} \quad$ B. Dupont ${ }^{c} \quad$ F. Menichettid $\quad$ U. Schuler ${ }^{e}$ \\ aDepartment of Haematology, Royal Free Hospital and School of Medicine, London, UK; bService Hematologie \\ Clinique, CHU Dijon, and 'Hôpital de L'Institut Pasteur, Paris, France; d Institute of Infectious Diseases,

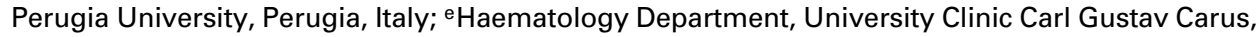 \\ Dresden, Germany
}

\section{Key Words}

Bone marrow transplantation · Fungal infection, systemic · Itraconazole · Malignancy, haematological • Neutropenia

\begin{abstract}
Effective prevention, or treatment, of invasive fungal infection in the neutropenic patient has hitherto been unsatisfactory because of either an inadequate anti-fungal spectrum of the agent or important toxicity. Itraconazole is effective against a broad spectrum of the opportunistic pathogens seen in Europe and North America. Prior problems with absorption, e.g. in the marrow transplant recipient, have been overcome with the introduction of an oral solution and an i.v. preparation. The deliberations of an expert meeting held in June, 1998 include recommendations on which patient requires one of these new preparations based on clinical trials, the dose and route. Important drug interactions are also detailed.
\end{abstract}

This is an expert report of a meeting held in London on 20 June 1998 on itraconazole. The meeting was supported by an unrestricted educational grant from Janssen-Pharmaceutica and Janssen Research Foundation, Beerse, Belgium.

\begin{tabular}{ll}
\hline KARGER & ( 1999 S. Karger AG, Basel \\
0001-5792/99/1011-0056\$17.50/0 \\
$\begin{array}{l}\text { Fax +4161306 12 34 } \\
\begin{array}{l}\text { E-Mail karger@karger.ch } \\
\text { www.karger.com }\end{array}\end{array}$ & $\begin{array}{l}\text { Accessible online at: } \\
\text { http://BioMedNet.com/karger }\end{array}$
\end{tabular}

\section{Introduction}

Systemic fungal infection is an increasing problem in patients receiving immunosuppressive chemotherapy for haematological malignancies and in bone marrow transplant recipients. Contributory factors include the use of broad-spectrum antibiotics, corticosteroids, central venous catheters, profoundly immunosuppressive chemotherapy, intensive irradiation protocols and mismatched or unrelated donor transplants, despite the increasing use of rooms with high-efficiency particulate air filtration.

Previously, most infections were by Candida species. Although infection by Candida albicans is decreasing, the incidence of non-C. albicans isolates is increasing [1]. In Europe, Aspergillus species are now the most frequently identified invasive pathogens. Mucorales are seen occasionally and any of a wide range of emerging fungi, such as Fusarium, Scedosporium and Trichosporon, may be involved $[2,3]$. Broad-spectrum antifungal therapy is therefore required.

Many fungal infections are diagnosed only at autopsy [4] because current diagnostic tools are largely inadequate; as a result, prophylaxis and empirical therapy play a key role in patient management. The agents used most frequently are amphotericin B (the treatment of choice for many years), fluconazole and itraconazole.

Professor H. Grant Prentice

Department of Haematology

Royal Free and University College Medical School

Royal Free Campus, Pond Street, London NW3 2QG (UK)

Tel. +44 171830 2300, Fax +44 171794 0645, E-Mail prentice@rfhsm.ac.uk 
Amphotericin B has a broad spectrum of activity (including against Candida and Aspergillus species) [5], but conventional formulations are associated with acute toxic reactions and nephrotoxicity [2]. New lipid-based preparations of amphotericin B are now available; each is likely to be at least as effective as and less nephrotoxic than the conventional formulations [6,7], but optimum therapeutic dosages require clarification.

Fluconazole is used extensively [8-12], particularly as prophylaxis, but it has a limited spectrum of activity (it is ineffective against Aspergillus and some non-C. albicans species, such as Candida krusei) and the emergence of drug resistance has been reported [13-16].

Itraconazole is active against a wide range of dermatophytes, yeasts and fungi (including Candida and Aspergillus species) [17], but the standard capsule formulation is less suitable for use in some patients because absorption from the capsules is impaired in patients with gastrointestinal epithelial damage [18]; in addition, because absorption depends on gastric acidity, the capsules must be taken with food to achieve optimum bioavailability; they may therefore be absorbed suboptimally by patients with restricted oral food intake [19-21].

The use of hydroxypropyl- $\beta$-cyclodextrin has enabled the development of two new itraconazole formulations (an oral solution and an intravenous preparation), which provide higher, more consistent plasma concentrations of itraconazole than the capsule formulation does [22-27] and should facilitate the effective use of this agent in a wider range of patients.

A meeting was held in London, UK, on 20 June 1998, to discuss the use of the itraconazole oral solution and intravenous formulations in neutropenic or otherwise immunosuppressed patients. Specific questions were addressed in a round-table discussion and pharmacokinetic and efficacy data were presented to facilitate informed debate. This publication is a summary of the practical recommendations made at the meeting regarding the use of the new itraconazole formulations in this patient population.

\section{Prophylaxis}

Which Patients Require Prophylaxis?

Prophylaxis with itraconazole was recommended for patients who are expected to have neutropenia (neutrophil count $\left.0.1-0.5 \times 10^{9} / 1\right)$ for at least 2 weeks or profound neutropenia (neutrophil count $<0.1 \times 10^{9} / 1$ ) for more than 1 week. Prophylaxis may not be required for patients receiving autologous peripheral stem cell transplants because they have a relatively short period of neutropenia (compared with bone marrow transplant recipients).

The incidence of systemic fungal infection depends not only on the severity of neutropenia but also on the underlying disease. Lower rates of infection (4-5\%) occur in patients undergoing autologous bone marrow transplantation, especially those with solid tumours receiving a colony-stimulating factor [28]; intermediate rates $(8 \%)$ are documented in patients with acute leukaemia $[11,12]$ and higher rates (16-18\%) are reported in patients undergoing allogeneic bone marrow transplantation for haematological malignancies [9,10]. The risk of Aspergillus infection in allogeneic bone marrow transplant recipients is higher if the patient is older, has acute myelogenous leukaemia beyond first remission, has graft-versus-host disease treated with high-dose steroids or is not treated in a laminar airflow room with high-efficiency particulate air filtration or when unrelated donors are used. In addition, the risk of Aspergillus infection is higher in patients with relapsing or progressive acute myelogenous leukaemia or other haematological malignancies if they receive high doses of gut-damaging chemotherapy, fludarabine or powerful immunosuppressive agents such as steroids.

\section{Have the New Itraconazole Formulations Been \\ Evaluated in the Prophylactic Setting?}

The itraconazole oral solution $(5 \mathrm{mg} / \mathrm{kg} / \mathrm{day})$ has been evaluated as prophylaxis during neutropenic episodes in three major studies; results are summarized in table 1. Study 1 was a double-blind, placebo-controlled trial with blinded review and standard antibiotics $(n=405)$ [29]. Prophylaxis was started at the same time as chemotherapy. Patients undergoing allogeneic bone marrow transplantation or receiving high-dose cytosine arabinoside were excluded. Study 2 and study 3 used similar patient populations, but allogeneic bone marrow transplant recipients were included in study 2 . Study 2 was an open, randomized comparison with fluconazole $100 \mathrm{mg} /$ day $(\mathrm{n}=$ 445) [30]. Study 3 was a double-blind, double-dummy comparison with oral amphotericin B $2 \mathrm{~g} /$ day $(\mathrm{n}=557)$, with blinded review and an interim analysis [31]; this trial was stopped prematurely because the anticipated incidence of aspergillosis was not reached in either arm.

Fewer fungal infections occurred in the itraconazole groups than in the comparison groups in all three studies (significant difference vs. placebo in study 1). Consequently, the use of intravenous amphotericin B therapy was also lower in the itraconazole group in all three stud- 
Table 1. Summary of data from three major prophylactic studies evaluating itraconazole oral solution

\begin{tabular}{|c|c|c|c|c|c|c|}
\hline & \multicolumn{2}{|l|}{ Study 1 [29] } & \multicolumn{2}{|l|}{ Study 2 [30] } & \multicolumn{2}{|l|}{ Study 3 [31] } \\
\hline & $\begin{array}{l}\text { itraconazole } \\
(\mathrm{n}=201)\end{array}$ & $\begin{array}{l}\text { placebo } \\
(\mathrm{n}=204)\end{array}$ & $\begin{array}{l}\text { itraconazole } \\
(\mathrm{n}=288)\end{array}$ & $\begin{array}{l}\text { fluconazole } \\
(\mathrm{n}=293)\end{array}$ & $\begin{array}{l}\text { itraconazole } \\
(\mathrm{n}=281)\end{array}$ & $\begin{array}{l}\text { amphotericin B } \\
(\mathrm{n}=276)\end{array}$ \\
\hline All fungal infections & $48^{*, a}$ & $68^{*, a}$ & 67 & 82 & 93 & 103 \\
\hline Deep aspergillosis & 4 & 1 & 0 & 4 & 5 & 9 \\
\hline Use of i.v. amphotericin B & $43^{* *}$ & $59 * *$ & $39 *$ & $58^{*}$ & 90 & 102 \\
\hline Death with proven deep fungal infection & 1 & 5 & $0^{*}$ & $4^{*}$ & 1 & 5 \\
\hline
\end{tabular}

$* \mathrm{p} \leq 0.05$ (statistical significance) $0.05<* * \mathrm{p} \leq 0.1$ (statistical trend). $\mathrm{n}=$ Number of patients.

a Proven deep fungal infections (itraconazole $n=5$, placebo $n=9$ ) plus suspected deep fungal infections requiring empirical amphotericin $B$ (itraconazole $n=43$, placebo $n=59$ ).

ies (significant difference vs. fluconazole in study 2; trend towards significant difference vs. placebo in study 1). This observation is of particular clinical relevance because of the risk of severe nephrotoxicity with intravenous amphotericin B. The incidence of deep aspergillosis was consistently low across the studies; indeed, the overall incidence of mould infection was low in all three studies, which may explain the lack of statistical difference between groups. Additionally, in study 1, significantly lower incidences of candidaemia (itraconazole $\mathrm{n}=1$, placebo $\mathrm{n}=8 ; \mathrm{p}<0.05$ ) and fewer deaths related to Candida infection (itraconazole $n=0$, placebo $n=4$ ) were seen in the itraconazole group than in the placebo group. Fewer deaths with proven deep fungal infection occurred in the itraconazole groups in all three studies (table 1).

The itraconazole intravenous formulation is currently under evaluation as prophylaxis for allogeneic bone marrow transplant recipients.

\section{Which Itraconazole Formulations Should Be Used for Prophylaxis?}

The itraconazole oral solution was considered to be appropriate for prophylaxis, starting from day 1 of chemotherapy. One week of the intravenous formulation and the oral solution thereafter was considered to be an appropriate prophylactic regimen for high-risk patients, such as allogeneic bone marrow transplant recipients. The intravenous formulation was considered to be appropriate for patients unable to take oral medication (i.e. those with chemotherapy-induced, severe, oral and intestinal mucositis). Further information is needed to assess the potential impact of interactions between azole antifungals and chemotherapeutic agents on multidrug resistance and the timing of prophylaxis.
Which Patients May Require Long-Term Prophylaxis?

Patients receiving corticosteroids, patients undergoing mismatched bone marrow transplantation, patients with graft-versus-host disease, patients who have received profoundly immunosuppressive chemotherapy (such as combinations containing fludarabine) or durable semi-intensive chemotherapy for acute lymphoblastic leukaemia and patients undergoing another course of myeloablative chemotherapy who have had a previous invasive fungal infection (such as aspergillosis) were considered to require long-term prophylaxis beyond the period of neutropenia.

\section{What Factors May Affect the Long-Term}

Administration of the Itraconazole Oral Solution?

Some patients receiving the itraconazole oral solution may experience cyclodextrin-associated diarrhoea, which is usually well tolerated; however, if the diarrhoea becomes problematic and gastrointestinal absorption is unimpaired, a switch from the oral solution during neutropenia to capsules after neutrophils have recovered was proposed. (Neutrophils are used as a marker of mucosal repair, except in graft-versus-host disease affecting the gastrointestinal tract.) Intermittent monitoring of the plasma concentration of itraconazole is advised if the capsule formulation is used in the long term.

\section{Empirical and Definitive Therapy}

Have the New Itraconazole Formulations Been Evaluated in the Treatment Setting?

The efficacy of the itraconazole oral solution in oral candidiasis [32-34] and oesophageal candidiasis [35] has been compared with that of fluconazole in HIV-positive

\footnotetext{
$\overline{58} \quad \overline{\text { Acta Haematol 1999;101:56-62 }}$
} 
individuals. In all four studies, the response rates were equivalent. In most cases, the causative organism was C. albicans.

The itraconazole intravenous formulation is under evaluation as definitive treatment for aspergillosis and candidiasis and as empirical therapy for fever that is unresponsive to antibiotics in patients with persistent neutropenia.

\section{Which Itraconazole Formulations Should Be Used for Treatment?}

One week of the itraconazole intravenous formulation and the oral solution thereafter were considered to be an acceptable regimen for empirical treatment.

An earlier switch to the itraconazole oral solution was also considered to be a viable option, given that an adequate plasma concentration of itraconazole is achieved after 2 days of treatment with the intravenous formulation [27]. Because the two new formulations have equivalent spectra of activity and bioavailability, only a patient's inability to take oral medication should delay a switch from intravenous itraconazole to the oral solution.

A longer overall period of treatment was considered to be required for aspergillosis than for candidiasis (non- $C$. albicans) but a precise duration could not be agreed. Treatment for 1 week beyond resolution of all diagnostic features of infection (fever, computed tomography scan) was considered the minimum requirement in patients whose neutrophils have recovered.

For patients who do not respond to itraconazole, a switch to amphotericin B was recommended (the choice of amphotericin B formulation should be made according to local practice and taking specific indication, renal function and concomitant use of other nephrotoxic drugs into consideration); no data are currently available on switching back to intravenous itraconazole in this setting.

\section{Have the New Itraconazole Formulations Been Evaluated in Patients with Fluconazole-Resistant Infections?}

At present, no data are available for neutropenic patients, but the itraconazole oral solution has been evaluated in three open trials in HIV-positive individuals with fluconazole-resistant or fluconazole-refractory oropharyngeal candidiasis [36-38]. Responses ranged from 60 to $80 \%$. Causative agents were C. albicans ( $75.4 \%$ of cases), Candida glabrata (17.4\%) and C. krusei (5.9\%). Response was achieved in 23 of 25 patients with a fluconazole-resistant C. glabrata infection.

\section{General Considerations}

\section{What Is the Target Plasma Concentration of \\ Itraconazole?}

Tentative interpretive minimal inhibitory concentration breakpoints for itraconazole have been established for mucosal candidal infections: susceptible 100-250 ng/ $\mathrm{ml}$, susceptible dependent on dose $250-500 \mathrm{ng} / \mathrm{ml}$, and resistant $\geq 1,000 \mathrm{ng} / \mathrm{ml}$ [39]. A plasma concentration of itraconazole of at least $250-500 \mathrm{ng} / \mathrm{ml}$ was therefore considered to be desirable.

Early pharmacokinetic data from autologous bone marrow transplant recipients show that use of the itraconazole oral solution $5 \mathrm{mg} / \mathrm{kg}$ once daily during remissioninduction treatment produced serum concentrations of itraconazole that reached (and exceeded) $500 \mathrm{ng} / \mathrm{ml}$ from day 8 onwards [22]. When itraconazole was given prophylactically, $86-100 \%$ of patients reached adequate levels after 12 days [29].

In patients who received a loading dose of intravenous itraconazole $200 \mathrm{mg}$ twice daily for 2 days followed by $200 \mathrm{mg}$ once daily from day 3 to day 7 , steady-state plasma concentrations of itraconazole of $250 \mathrm{ng} / \mathrm{ml}$ were achieved by day 1 and $500 \mathrm{ng} / \mathrm{ml}$ by day 2 . In addition, a plasma concentration of at least $500 \mathrm{ng} / \mathrm{ml}$ was maintained after a switch to the oral solution $200 \mathrm{mg}$ twice daily at day 7 [27].

Both new itraconazole formulations therefore rapidly produce target plasma concentrations of the drug. (Itraconazole concentrations were obtained by high-performance liquid chromatography.)

\section{Is Monitoring Required?}

For both the oral solution and the intravenous formulation of itraconazole, monitoring of the plasma drug concentration was considered to be unnecessary (given the reliable pharmacokinetic profiles) [40] and impractical (given the short anticipated duration of neutropenia). Monitoring plasma itraconazole concentrations may be useful when the oral solution or the intravenous formulation is used for treatment of documented infection.

\section{How Should the Itraconazole Oral Solution Be Taken to Achieve Optimum Bioavailability?}

In healthy volunteers, the relative bioavailability of the itraconazole oral solution exceeds that of the capsule formulation when both are taken with food [31]. In addition, unlike the capsule formulation, bioavailability is increased with the oral solution under fasting conditions (fig. 1) [41, 42]. 


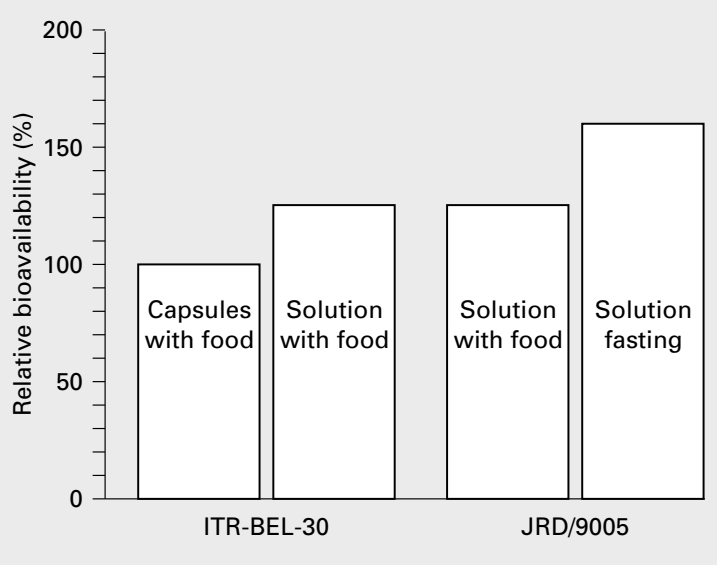

Fig. 1. Itraconazole capsules and oral solution in healthy volunteers: effect of food on oral bioavailability at steady state

\section{Can the New Itraconazole Formulations Be Used in}

Patients with Impaired Gastrointestinal Absorption?

The itraconazole oral solution was considered to be appropriate for allogeneic bone marrow transplant recipients with impaired gastrointestinal absorption, including that caused by severe graft-versus-host disease of the intestine. However, the intravenous formulation was recommended for patients with severe mucositis.

\section{What Other Factors Might Influence the Choice of Itraconazole Formulation?}

If a patient is unconscious or intubated, oral administration of any antifungal agent is not always appropriate.

The recommendation was made to switch patients to the itraconazole intravenous formulation if they experience unacceptable gastrointestinal upset with the oral solution and do not require long-term treatment. A trial is in progress in the UK to examine the pharmacokinetics of switching from the itraconazole oral solution to the intravenous formulation, to determine whether a loading dose is still appropriate in this setting.

\section{Which Drugs Should Not Be Given with Itraconazole or Require Special Precautions?}

The following drugs should not be given concurrently with itraconazole: terfenadine, astemizole, cisapride, pimozide, HMG-CoA reductase inhibitors such as simvastatin and lovastatin, oral midazolam or triazolam.

Inhibition of cytochrome $\mathrm{P} 450$ by itraconazole may lead to reduced clearance of oral anticoagulants, digoxin, cyclosporin A, systemic methylprednisolone, vinca alkaloids [43, 44], dihydropyridine calcium channel blockers, quinidine, intravenous midazolam, clarithromycin, phenytoin, tacrolimus and busulphan [45]. These drugs require monitoring and may require dose reductions. Other drugs may increase the elimination of itraconazole (rifampicin, carbamazepine and isoniazid) and may lead to subtherapeutic blood levels of itraconazole.

\section{Which Drugs Are Not Affected by Itraconazole?}

In vitro studies have shown that no interactions on plasma protein binding occur between itraconazole and imipramine, propranolol, diazepam, cimetidine, indomethacin, tolbutamide or sulphamethazine.

No interaction between itraconazole and zidovudine or omeprazole and no inducing effects of itraconazole on the metabolism of ethinyloestradiol and norethisterone have been observed.

\section{How Will the New Itraconazole Formulations Contribute to the Management of Systemic Fungal Infections?}

The new formulations of itraconazole are expected to play an important role in the management of systemic fungal infection for several reasons. First, they provide high, consistent plasma concentrations of itraconazole. With the intravenous formulation, adequate plasma concentrations of itraconazole are achieved rapidly (in 2 days). With the oral solution, optimum bioavailability is achieved under fasting conditions (whereas the capsule formulation must be taken with food). For both the oral solution and the intravenous formulation, monitoring of the plasma concentration of itraconazole is unnecessary. Furthermore, allogeneic bone marrow transplant recipients with impaired gastrointestinal absorption caused by severe graft-versus-host disease can still receive the itraconazole oral solution, whereas patients who cannot swallow or tolerate the oral solution can receive itraconazole by intravenous infusion.

Overall, therefore, the new itraconazole formulations should provide clinicians with greater flexibility in the management of systemic fungal infection in neutropenic haematological patients and they are expected to reduce the use of intravenous amphotericin B, with resultant patient benefit.
60

Acta Haematol 1999;101:56-62
Prentice/Caillot/Dupont/Menichetti/ Schuler 


\section{References}

1 Wingard JR: Importance of Candida species other than C. albicans as pathogens in oncology patients. Clin Infect Dis 1995;20:115-125.

2 Working Party of the British Society for Antimicrobial Chemotherapy: Therapy of deep fungal infection in haematological malignancy. $\mathrm{J}$ Antimicrob Chemother 1997;40:779-788.

3 Prentice AG: Systemic fungal infection in haematological malignancy - Current therapy. Curr Med Lit Leuk Lymphoma 1997;5:63-70.

4 Jandrlic M, Kalenic S, Labar B, Nemet D, Jakic-Razumovic J, Mrsic M, Plecko V, Bogdanic $\mathrm{V}$ : An autopsy study of systemic fungal infections in patients with hematologic malignancies. Eur J Clin Microbiol Infect Dis 1995;14: 768-774.

5 Gallis HA, Drew RH, Pickard WW: Amphotericin B: 30 years of clinical experience. Rev Infect Dis 1990;12:308-329.

6 Hiemenz JW, Walsh TJ: Lipid formulations of amphotericin B: Recent progress and future directions. Clin Infect Dis 1997;22(suppl 2):S133-S144.

7 Prentice HG, Hann IM, Herbrecht R, Aoun M, Kvaloy S, Catovsky D, Pinkerton CR, Schey SA, Jacobs F, Oakhill A, Stevens RF, Darbyshire PJ, Gibson BE: A randomized comparison of liposomal versus conventional amphotericin B for the treatment of pyrexia of unknown origin in neutropenic patients. $\mathrm{Br} \mathrm{J}$ Haematol 1997;98:711-718.

8 Rex JH, Bennett JE, Sugar AM, Pappas PG, van der Horst CM, Edwards JE, Washburn RG, Scheld WM, Karchmer AW, Dine AP, et al: A randomized trial comparing fluconazole with amphotericin B for the treatment of candidemia in patients without neutropenia. N Engl J Med 1994:331:1325-1330.

9 Slavin MA, Osborne B, Adams R, Levenstein MJ, Schoch HG, Feldman AR, Meyers JD, Bowden RA: Efficacy and safety of fluconazole prophylaxis for fungal infections after marrow transplantation - A prospective, randomized, double-blind study. J Infect Dis 1995;171: 1545-1552.

10 Goodman JL, Winston DJ, Greenfield RA, Chandrasekar PH, Fox B, Kaizer H, Shadduck RK, Shea TC, Stiff P, Friedman DJ, et al: A controlled trial of fluconazole to prevent fungal infections in patients undergoing bone marrow transplantation. N Engl J Med 1992;326:845851.

11 Schaffner A, Schaffner M: Effect of prophylactic fluconazole on the frequency of fungal infections, amphotericin B use, and health care costs in patients undergoing intensive chemotherapy for hematologic neoplasias. J Infect Dis 1995; 172:1035-1041.

12 Winston DJ, Chandrasekar PH, Lazarus HM, Goodman JL, Silber JL, Horowitz H, Shadduck RK, Rosenfeld CS, Ho WG, Islam MZ, et al: Fluconazole prophylaxis of fungal infections in patients with acute leukemia. Results of a randomized placebo-controlled, double-blind, multicenter trial. Ann Intern Med 1993;118: 495-503.
13 Wingard JR, Merz WG, Rinaldi MG, Johnson TR, Karp JE, Saral R: Increase in Candida krusei infection among patients with bone marrow transplantation and neutropenia treated prophylactically with fluconazole. N Engl J Med 1991;325:1274-1277.

14 Hitchcock CA, Pye GW, Troke PF, Johnson EM, Warnock DW: Fluconazole resistance in Candida glabrata. Antimicrob Agents Chemother 1993;37:1962-1965.

15 Wingard JR: Infections due to resistant Candida species in patients with cancer who are receiving chemotherapy. Clin Infect Dis 1994; 19(suppl 1):S49-S53.

16 Lee Y-P, Goldman M, Vidt DG: The role of azole antifungal agents for systemic antifungal therapy. Cleve Clin J Med 1997;64:99-104.

17 Van Cutsem J, Van Gerven F, Janssen PAJ: The in vitro and in vivo antifungal activity of itraconazole; in Fromtling RA (ed): Recent Trends in the Discovery, Development and Evaluation of Antifungal Agents. Barcelona, Prous Science Publishers, 1987, pp 177-192.

18 Boogaerts MA, Verhoef GE, Zachee P, Demuynck H, Verbist L, De Beule K: Antifungal prophylaxis with itraconazole in prolonged neutropenia: Correlation with plasma levels. Mycoses 1989;32(suppl 1):103-108.

19 Lim SG, Sawyer AM, Hudson M, Sercombe J, Pounder RE: Short report: The absorption of fluconazole and itraconazole under conditions of low intragastric acidity. Aliment Pharmacol Ther 1993; 7:317-321.

20 Zimmermann T, Yeates RA, Albrecht M, Laufen $\mathrm{H}$, Wildfeuer A: Influence of concomitant food intake on the gastrointestinal absorption of fluconazole and itraconazole in Japanese subjects. Int J Clin Pharmacol Res 1994;14:8793.

21 Zimmermann T, Yeates RA, Laufen H, Pfaff $\mathrm{G}$, Wildfeuer A: Influence of concomitant food intake on the oral absorption of two triazole antifungal agents, itraconazole and fluconazole. Eur J Clin Pharmacol 1994;46:147-150.

22 Prentice AG, Warnock DW, Johnson SA, Taylor PC, Oliver DA: Multiple dose pharmacokinetics of an oral solution of itraconazole in patients receiving chemotherapy for acute myeloid leukaemia. J Antimicrob Chemother 1995;36:657-663.

23 Prentice AG, Warnock DW: Itraconazole more bioavailable in solution. Blood 1996;88:36623663.

24 Cartledge JD, Midgely J, Gazzard BG: Itraconazole solution: Higher serum drug concentrations and better clinical response rates than the capsule formulation in acquired immunodeficiency syndrome patients with candidosis. J Clin Pathol 1997;50:477-480.

25 Barone JA, Moskovitz BL, Guarnieri J, Hassell AE: Enhanced bioavailability of itraconazole solution compared with capsules in healthy volunteers. Pharmacotherapy 1997;17:194195.
26 Vandewoude K, Vogelaers D, Decruyenaere J, Jaqmin P, De Beule K, Van Peer A, Woestenborghs R, Groen K, Colardyn F: Concentrations in plasma and safety of 7 days of intravenous itraconazole followed by 2 weeks of oral itraconazole solution in patients in intensive care units. Antimicrob Agents Chemother 1997;41:2714-2718.

27 Boogaerts M, Michaux J-L, Bosly A, Van Hoof A, Jacqmin P, Van Peer A, Woestenborghs R, Stoffels P, Groen K, De Beule K: Pharmacokinetics and safety of seven days' intravenous itraconazole followed by two weeks' oral itraconazole solution in patients with haematological malignancy (abstract A87). 36th Interscience Conference on Antimicrobial Agents and Chemotherapy, New Orleans, 1996.

28 Perfect JR, Klotman ME, Gilbert CC, Crawford DD, Rosner GL, Wright KA, Peters WP: Prophylactic intravenous amphotericin B in neutropenic autologous bone marrow transplant recipients. J Infect Dis 1992;165:891897.

29 Menichetti F, Del Favero A, Martino P, GIMEMA Infection Program: Itraconazole oral solution prophylaxis of fungal infections in neutropenic patients with haematologic malignancies. A randomized, placebo-controlled, double-blind, multicenter trial. Clin Infect Dis, in press.

30 Morgenstern GR, Prentice AG, Prentice HG, Ropner JE, Schey SA, Warnock DW: Itraconazole (IT) oral solution vs fluconazole $(\mathrm{F})$ suspension for antifungal prophylaxis in neutropenic patients (abstract LM34). 36th Interscience Conference on Antimicrobial Agents and Chemotherapy, New Orleans, 1996.

31 Harousseau J-L, Stamatoullas A, Dekker A, De Bock B, Bassaris H, Fassas A, Vazquez L, Seifert W, De Beule K: Prophylaxis of fungal infections in haematological malignancy: A double blind trial comparing itraconazole oral solution to amphotericin B capsules (abstract). 38th Interscience Conference on Antimicrobial Agents and Chemotherapy, San Diego, 1998.

32 Gazzard B, Vandercam B, Cartier F, Mathiesen L, Stoffels P, De Beule K: Effect of itraconazole in the treatment of oral candidosis and candida oesophagitis in HIV+ patients. A double-blind, double-dummy, randomized comparison with fluconazole (abstract). Can J Infect Dis 1995;6(suppl C):224C.

33 Frechette G, De Beule K, Weinke W, Tchamouroff S, Stoffels P: Effects of itraconazole in the treatment of oral candidosis in HIV patients, a double-blind, double-dummy, randomized comparison with fluconazole (abstract 1219). 35th Interscience Conference on Antimicrobial Agents and Chemotherapy, San Francisco, 1995.

34 Graybill JR, Vazquez J, Darouiche RO, Morhart R, Greenspan D, Tuazon C, Wheat J, Carey J, Leviton I, Hewitt RG, MacGregor RR, Valenti W, Restrepo M, Moskovitz BL: Randomized trial of itraconazole oral solution for oropharyngeal candidiasis in HIV/AIDS patients. Am J Med 1998;104:33-39. 
35 Wilcox CM, Darouiche RO, Laine L, Moskovitz BL, Mallegol I, Wu J: A randomized, double-blind comparison of itraconazole oral solution and fluconazole tablets in the treatment of esophageal candidiasis. J Infect Dis 1997;176: 227-232.

36 Eichel M, Just-Nübling G, Helm EB, Stille W: Itraconazole suspension in the treatment of HIV-infected patients with fluconazole-resistant oropharyngeal candidiasis and esophagitis. Mycoses 1996;39(suppl 1):102-106.

37 Phillips P, Zemcov J, Mahmood W, Montaner J, Craib K, Clarke A: Itraconazole cyclodextrin solution for fluconazole-refractory oropharyngeal candidosis in AIDS: Correlation of clinical response with in vitro susceptibility. AIDS 1996;10:1369-1376.

38 Fessel WJ, Merrill KW, Ward DJ, Moskovitz BL, Benken C, Oleka N, Grimwood H: Itraconazole oral solution for the treatment of fluconazole-refractory oropharyngeal candidiasis in HIV-positive patients (abstract 327). 4th Conference on Retroviruses and Opportunistic Infections, Washington, 1997.
39 Rex JH, Pfaller MA, Galgiani JN, Bartlett MS, Espinel-Ingroff A, Ghannoum MA, Lancaster M, Odds FC, Rinaldi MG, Walsh TJ, Barry $\mathrm{AL}$ : Development of interpretive breakpoints for antifungal susceptibility testing: Conceptual framework and analysis of in vitro-in vivo correlation data for fluconazole, itraconazole, and candida infections. Subcommittee on Antifungal Susceptibility Testing of the National Committee for Clinical Laboratory Standards. Clin Infect Dis 1997;24:235-247.

40 Prentice AG, Warnock DW, Morgenstern GR, Prentice HG, Ropner JE, Schey SA: Serum concentrations of itraconazole in neutropenic patients receiving itraconazole/cyclodextrin solution (abstract 0787). 39th Annual American Society of Hematology Meeting, San Diego, 1997.
41 Van de Velde VJS, Van Peer AP, Heykants JJP, Woestenborghs RJH, Van Rooy P, De Beule KL, Cauwenbergh GFMJ: Effect of food on the pharmacokinetics of a new hydroxypropyl-beta-cyclodextrin formulation of itraconazole. Pharmacotherapy 1996;16:424-428.

42 Barone JA, Moskovitz BL, Guarnieri J, Hassell AE, Colaizzi JL, Bierman RH, Jessen L: Food interaction and steady-state pharmacokinetics of itraconazole oral solution in healthy volunteers. Pharmacotherapy 1998;18:295-301.

43 Böhme A, Ganser A, Hoelzer D: Aggravation of vincristine-induced neurotoxicity by itraconazole in the treatment of adult ALL. Ann Hematol 1995;71:311-312.

44 Gillies J, Hung KA, Fitzsimons E, Soutar R: Severe vincristine toxicity in combination with itraconazole. Clin Lab Haematol 1998;20:123124.

45 Buggia I, Zecca M, Alesandrino EP, Locatelli F, Rosti G, Bosi A, Pession A, Rotoli B, Majolino I, Dallorso A, Regazzi MB: Itraconazole can increase systemic exposure to busulfan in patients given bone marrow transplantation (GITMO). Anticancer Res 1996;16:20832088. 